\title{
Common Diagnostic Challenges in the Histopathologic Diagnosis of Neuroendocrine Lung Tumors: A Case Report
}

\author{
Monica Valente $^{\mathrm{a}} \quad$ Laura Catena $^{\mathrm{a}}$ Massimo Milione $^{\mathrm{b}}$ \\ Sara Pusceddu ${ }^{a}$ Barbara Formisano ${ }^{a} \quad E^{2}$ ilio Bajetta ${ }^{a}$ \\ ${ }^{\mathrm{a}}$ Medical Oncology Unit 2 and ${ }^{\mathrm{b} P a t h o l o g y}$ Unit, Fondazione IRCCS, \\ Istituto Nazionale Tumori, Milan, Italy
}

\section{Key Words}

Bronchial carcinoid $\cdot$ Neuroendocrine $\cdot$ Lung $\cdot$ Histopathologic findings $\cdot$ Misdiagnosis

\begin{abstract}
Bronchopulmonary neuroendocrine tumors are an uncommon group of neoplasms, accounting for about $20 \%$ of all lung carcinomas, arising from stem cells of the bronchial epithelium known as Kulchitsky cells. In the past, these tumors were grouped among benign or less aggressive malignant pulmonary tumors. Currently, according to the 2004 World Health Organization categorization, these tumors are separated into 4 subtypes characterized by increasing biologic aggressiveness: low-grade (typical carcinoid; TC), intermediate-grade (atypical carcinoid; AC) and high-grade (large-cell neuroendocrine carcinoma, LCNEC, and small-cell lung carcinoma, SCLC). They differ by morphologic, immunohistochemical and structural features. At histopathologic analysis, these tumors share progressive increase in a number of mitotic figures per 10 high-power fields and in the extent of necrosis, with TC having the lowest values and SCLC having the highest. TCs and ACs make up approximately $1-2 \%$ of all primary lung tumors. Differentiating ACs from TCs or LCNEC and SCLC is clinically important because the treatment modalities and prognoses for these types of tumors are different. We report a case of misdiagnosis of bronchopulmonary neuroendocrine tumor in a young woman which has heavily influenced her clinical history.
\end{abstract}

\section{Introduction}

Neuroendocrine lung tumors arise from a population of neuroendocrine cells normally present in the bronchoalveolar structures and are characterized by secretory activity and 


\begin{tabular}{c|l|l|l}
$\begin{array}{c}\text { Case Reports in } \\
\text { Oncology }\end{array}$ & $\begin{array}{l}\text { Case Rep Oncol 2010;3:202-207 } \\
\text { Dol: } 10.1159 / 000317313\end{array}$ & Published online: July 2, 2010 & $\begin{array}{l}\odot \text { 2010 S. Karger AG, Basel } \\
\text { ISSN 1662-6575 } \\
\text { www.karger.com/cro }\end{array}$ \\
\hline
\end{tabular}

ability to take up and decarboxylate the amine precursors (APUD system cells) [1]. These neuroendocrine phenotypical and morphological characteristics are present within a broad spectrum of histologies of lung neuroendocrine tumors (NETs), from relatively indolent typical carcinoids (TCs) to histologically high-grade, biologically aggressive tumors, as large-cell neuroendocrine carcinomas (LCNEC) and small-cell lung cancers.

The spectrum of pulmonary NETs, according to the 2004 World Health Organization (WHO) categorization, includes 4 subtypes characterized by increasing biologic aggressiveness: TCs and atypical carcinoids (ACs) are categorized together as carcinoids, LCNEC is considered a subgroup of large-cell carcinomas and small-cell lung carcinoma (SCLC) as an independent category [2].

Bronchopulmonary (BP) TCs and ACs are uncommon, representing 1-2\% of all pulmonary neoplasms; these variants are associated with relatively slow growth, and generally show a favorable outcome [3]. The TC subtype is predominant (80-90\%), and occurs most frequently in the 5th and 6th decades of life [4]. The most important difference between typical and atypical form is represented by the mitotic index. TCs have $<2$ mitoses per $\mathrm{mm}^{2}$ in 10 high-power fields (HPF) without signs of necrosis, while ACs are characterized by $2-10$ mitoses per $\mathrm{mm}^{2} / 10 \mathrm{HPF}$ and/or foci of necrosis. The LCNEC and SCLC subtypes are the most malignant of neuroendocrine lung tumors with a 5-year survival that, up to date, remains very poor. In particular, for the SCLC form the necrosis is typically extensive and the mitotic rate is very high with $>10$ mitoses $/ 2 \mathrm{~mm}^{2}$.

Nevertheless, diagnosis of BP carcinoids can be difficult and they may be mistaken for SCLC. A review of pathologic material by an experienced pathologist is important prior to diagnosis and specific treatments in this type of tumors.

In combination with the histologic appearance, the cell proliferation characterized by low labeling index Ki67 (MIB1) $<20 \%$ seems to be the most useful marker to distinguish the low-grade from the high-grade malignancy subgroups within the BP NETs. In particular, the immunoreactivity for nuclear markers (especially Ki67) is easily accessible and may be helpful in the differential diagnosis between TCs/ACs and SCLCs, high-grade NETs being characterized by a proliferative cell fraction much higher than that of carcinoids (MIB1 > 50\%). Several peptide and amine markers, including chromogranin A $(\mathrm{CgA})$, neuron-specific enolase (NSE), serotonin, synaptophysin, and adrenocorticotropic hormone $(\mathrm{ACTH})$, can provide us with further tools in order to better establish a differential diagnosis [5].

Molecular genetic changes may be useful as an adjunctive element to differentiate TCs from ACs. Retinoblastoma gene (13q13) and p53 (17p13) mutations, multiple endocrine neoplasia (MEN) 1 gene activation (11q13), and telomerase activity are particularly frequent in ACs if compared with TCs [4].

We report a case of a young woman with misdiagnosis of BP NET which has heavily influenced her clinical story.

\section{Case Report}

A 41-year-old symptomatic female patient, nonsmoker, following the onset of cough and low-grade fever despite empirical antibiotic therapy, underwent chest radiogram, which revealed an uneven area in the right lung, near the hilum. Because symptoms persisted after empirical antibiotic therapy, a CT scan was performed. Thorax CT scan documented a nodule in the right lung, near the hilum, 2 millimetric nodules in the left lung, in the lower lobe, and subcarinal lymphadenopathies. Bronchoscopy documented compression 'ab-aestrinseco' of the middle lobar bronchus. Cytological examination of fine-needle aspiration specimens showed atypical cells immunohistochemistry-positive for cytokeratin 


\begin{tabular}{c|l|l|l}
$\begin{array}{c}\text { Case Reports in } \\
\text { Oncology }\end{array}$ & $\begin{array}{l}\text { Case Rep Oncol 2010;3:202-207 } \\
\text { Dol: } 10.1159 / 000317313\end{array}$ & Published online: July 2, 2010 & $\begin{array}{l}\odot \text { 2010 S. Karger AG, Basel } \\
\text { ISSN 1662-6575 } \\
\text { www.karger.com/cro }\end{array}$ \\
\hline
\end{tabular}

MNF116, indicative of infiltration of small-cell lung cancer. Brain and abdomen CT scan did not show metastases. After 5 cycles of chemotherapy with cisplatin and etoposide and radiotherapy on mediastinum, the patient was referred to surgery (sleeve bilobectomy, pericardial resection and mediastinal lymphadenectomy). Histological examination showed an AC tumor (Ki67 > 2\%) with pathological staging pT2 N2. During the follow-up, the patient was subjected to CT scan every 6 months and then every year, to inspect the 2 millimetric nodules in the controlateral lung. After 8 years, CT scan documented an increase in the size of 1 of the 2 nodules in the lower lobe of the left lung, confirmed by PET (SUV5). The patient was referred to surgery (typical subsegmentectomy and mediastinal lymphadenectomy). Histological examination documented TC (Ki67 < 2\%), pT1 N1 as pathologic staging.

The patient was reassessed 8 months after surgery. CT and PET were negative for cancer, but blood test showed hypercalcemia $(14 \mathrm{mg} / \mathrm{dl})$. The patient did not report symptoms related to hypercalcemia. Therefore, neck ultrasound and thyroid scintigraphy were performed, and both revealed an increase in size of the right parathyroid gland. Then the patient underwent surgical excision.

\section{Discussion}

The presence of 3 distinct histological types of BP NETs in the same subject is unusual. Sporadic lung carcinoids may occur as a component $(\sim 5 \%)$ of the familial endocrine cancer syndrome multiple neuroendocrine neoplasia 1 (MEN1); in contrast, in poorly differentiated lung NETs (SCLC and LCNEC), this condition was rarely identified [6].

Analyzing the patient's family history, we learned that her mother had ZollingerEllison syndrome, a cousin had pancreatic neuroendocrine carcinoma and parathyroid adenoma and an uncle underwent surgery for a parathyroid adenoma. All this is strongly suggestive for the presence of MEN1 syndrome. Thus, the patient and her children will be subjected to genetic counseling and evaluation for MEN1 gene mutation. Consistent with our hypothesis, our histological review documented AC on the first cytological diagnosis, with immunohistochemical positivity for $\mathrm{CgA}$, synaptophysin and $\mathrm{Ki} 67: 5.3 \%$, while it confirmed the diagnosis of ACs and TCs, after lung surgery, according to WHO classification (fig. 1, fig. 2, fig. 3) [7].

\section{Conclusion}

This case report demonstrates that diagnosis by cytologic sampling can be confounding and it alone does not allow a correct and complete characterization of pulmonary tumors. Therefore, a careful histological evaluation is strongly recommended in particular in lung NETs [8].

It is also important that the diagnostic iter must be followed, as far as possible, in a specialized center, especially when we are faced with rare neoplastic diseases, as in this case. 
Fig. 1. First diagnosis of SCLC. Bronchial biopsy stained for CgA: rare positive elements dispersed in fibrosis (arrow), elements with features of molding are negative.

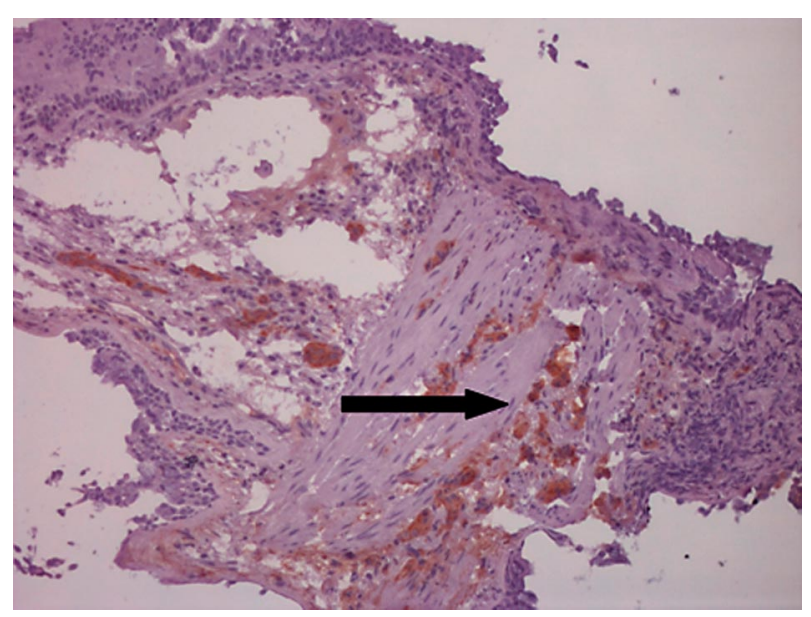

Fig. 2. First surgery. Right lung segment stained with CgA: AC with positive elements in fibrosis (arrow) similar to neoplastic cells in figure 1.

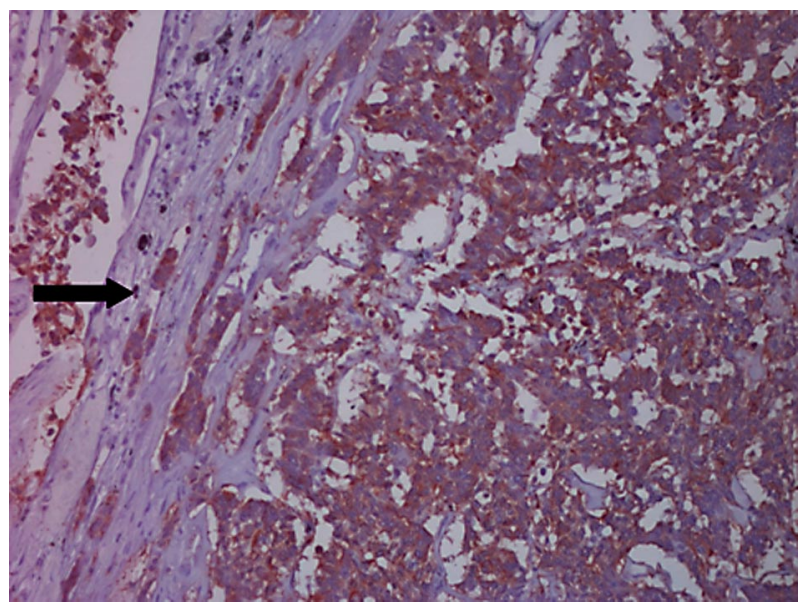


Fig. 3. Second surgery. Left lung segment stained for MIB1/Ki67: TC with rare cells present nuclear staining (arrow).

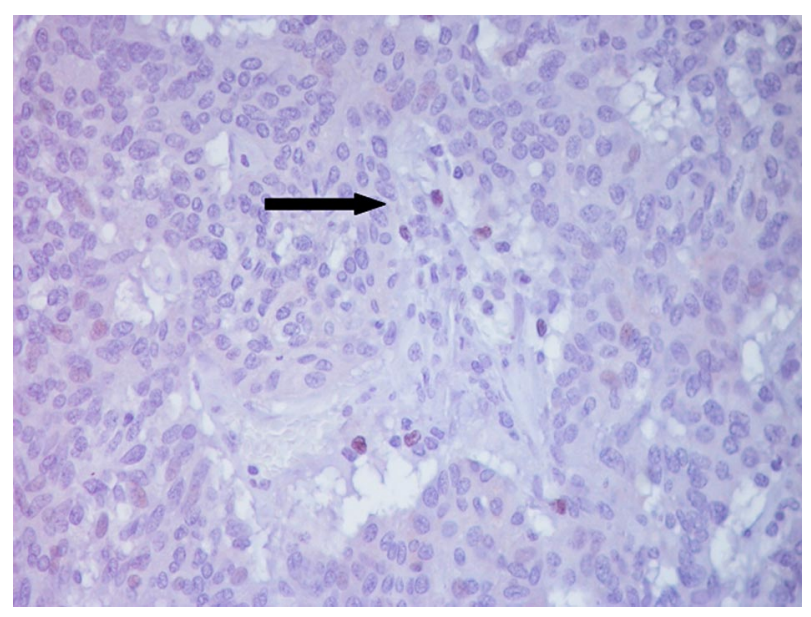




\section{References}

1 Pearse AG: The cytochemistry and ultrastructure of polypeptide hormone producing cells of APUD series and the embryologic, physiologic and pathologic implications of the concept. J Histochem Cytochem 1969;17:303-313.

2 Travis WD, Corrin B, Shimosato Y, Brambilla E: The histological typing of lung and pleural tumors; in WHO/IASLC Classification of Lung and Pleural Tumors. 3rd edition, Springer, Berlin, 1999.

-3 Chughtai TS, Morin JE, Sheiner NM, Wilson JA, Mulder DS: Bronchial carcinoid - twenty years' experience defines a selective surgical approach. Surgery 1997;122:801-808.

-4 Gustafsson BI, Kidd M, Chan A, Malfertheiner MV, Modlin IM: Bronchopulmonary neuroendocrine tumors. Cancer 2008;113:5-21.

5 Pelosi G, Rodriguez J, Viale G, Rosai J: Typical and atypical pulmonary carcinoid tumor overdiagnosed as small-cell carcinoma on biopsy specimens: a major pitfall in the management of lung cancer patients. Am J Surg Pathol 2005;29:179-187.

-6 Walch AK, Zitzelsberger HF, Aubele MM, Mattis AE, Bauchinger M, Candidus S, Präuer HW, Werner M, Höfler H: Typical and atypical carcinoid tumors of the lung are characterized by $11 \mathrm{q}$ deletions as detected by comparative genomic hybridization. Am J Pathol 1998;153:1089-1098.

7 Beasley MB, Brambilla E, Travis WD: The 2004 World Health Organization classification of lung tumors. Semin Roentgenol 2005;40:90-97.

$>8$ Öberg K, Jelic S: Neuroendocrine bronchial and thymic tumors: ESMO clinical recommendation for diagnosis, treatment and follow-up. Ann Oncol 2009;20:147-149. 